\title{
Improvement in Efficiency of Solar Photovoltaic Power System
}

\author{
Amit Tripathi, Rajesh Kumar
}

\begin{abstract}
The present paper relates to solar photovoltaic power system. In this paper the work is done on improving the efficiency of solar photovoltaic power system. In a Photovoltaic system the light coming from sun is directly converted into solar energy. This system as a source of energy becomes very popular nowadays due to some existing benefits like pollution free production of energy and free availability of sun light which is inexhaustible in nature. The main drawback is only output power which is still low, there is a requirement to improve the system. A technique called MPPT is used to track the maximum sun light coming at a particular point to produce maximum power. In this paper tracker works with an incremental conductance algorithm. In the paper simulations are taken to identify the maximum power point by MPPT.
\end{abstract}

Index Terms-PV module, MPPT tracker, Incremental conductance algorithm, MATLAB.

\section{INTRODUCTION}

The semiconductors generally exhibit photo-Photovoltaic effect (PV), therefore these materials can be applied to generate electricity, and these materials convert solar energy into electrical energy directly. A PV system uses various solar panels, solar panel is a collection of various solar cells used for supplying power. Energy generated from photo voltaic modules provides several benefits, like, less maintenance requirement and pollution free etc...Today, PV collection arrays are employed in several applications, like in battery chargers, satellite power systems, water pumping systems, grid connected PV systems and solar hybrid vehicles. The systems generates energy in accordance with obtained solar radiation, value of temperature and the amount of voltage generated by the photovoltaic module. There are 2 disadvantages related to the system wherein $1^{\text {st }}$ one is efficiency is in order of $9-17 \%$ which is extremely low, in particular conditions like presence of low irradiation and the value of generated electric power by means of sun radiations fluctuates constantly with different environmental conditions. Various methods has been implemented to compensate the problem of efficiency, and these methods include "Maximum power point tracking" (MPPT) is pleaded. In this methodology of Maximum Power Point Tracking, an algorithm is burned in charge controllers that are used for extracting maximum value of existing power from associated PV module under definite circumstances.

Revised Version Manuscript Received on 10 September, 2019.

Amit Tripathi, Department of Electronics \& Communication Engineering, Noida Institute of Engineering and Technology, Uttar Pradesh, India.(Email: researchnietip@gmail.com)

Dr. Rajesh Kumar, Department of Physics, Noida Institute of Engineering and Technology, Uttar Pradesh, India.(Email: researchnietip@gmail.com)
The term "maximum power point" is a value of voltage at which PV generates maximum amount of power. The variation in maximum power changes with coming radiation, environmental temperature and temperature of solar cell. There are many algorithms for tracking maximum operating power have been projected. An algorithm incremental conductance has been used for tracking purpose.

\section{MPP TRACKING}

Maximum power can be generated by changing and finding a point of operation for photovoltaic module to get the point of maximum power and it can be done with the help of an electronic system called as 'Maximum Power Point Tracking (MPPT)'. The system MPPT does not work automatically, in this modules move physically for getting the maximum amount of light coming from sun. Mechanical tracking system for tracking maximum power point that is completely different from MPPT can be used in combination with each other to get better results. It is observed that a usual module yields $17 \mathrm{~V}$ power voltage when it is checked at a cell temperature of 25 degree $\mathrm{C}$; and the variation in the voltage can be in-between $15 \mathrm{~V}$ and $18 \mathrm{~V}$ on for very hot and cold day respectively. Figure 1 illustrates a block diagram of the PV module with an MPPT. The employment of MPPT's is most operative in the seasons of winter, cloudy or hazy when the extra power is needed the most.

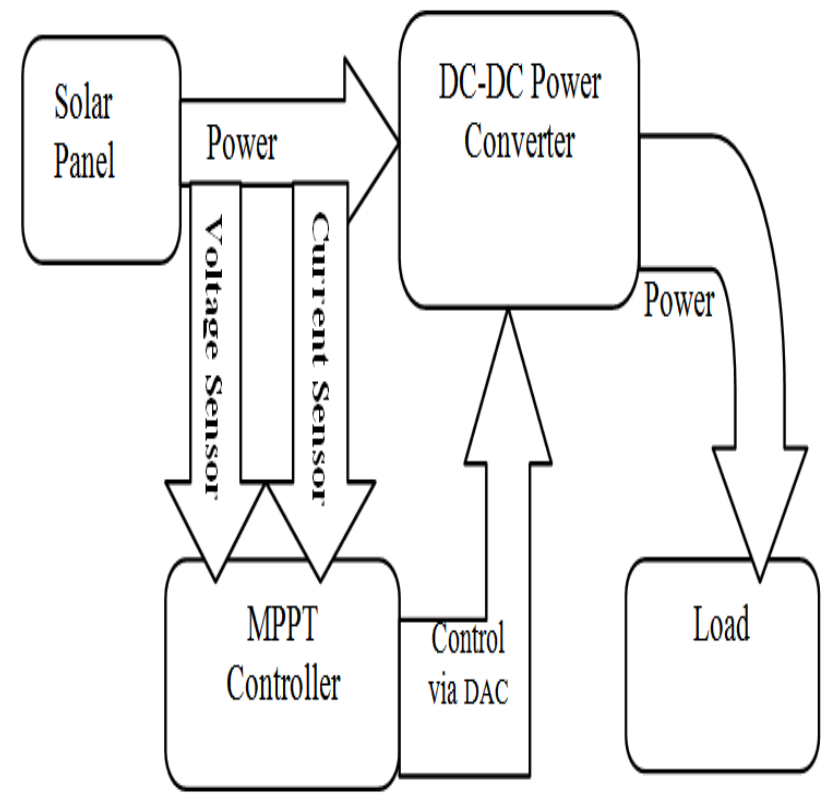

Figure 1: Block diagram of PV module with MPPT 


\section{IMPROVEMENT IN EFFICIENCY OF SOLAR PHOTOVOLTAIC POWER SYSTEM}

\section{MPPT ALGORITHM}

In the paper algorithm which has been used by the MPPT system is an 'Incremental Conductance Algorithm' chosen from various algorithms and usually used because of easy implementation. The algorithm works on the principle is that the terminal voltage of the array is always adjusted in accordance with the MPP voltage it uses instantaneous value and incremental value of conductance of the PV module. Figure 2 represents the flow method of the algorithm.

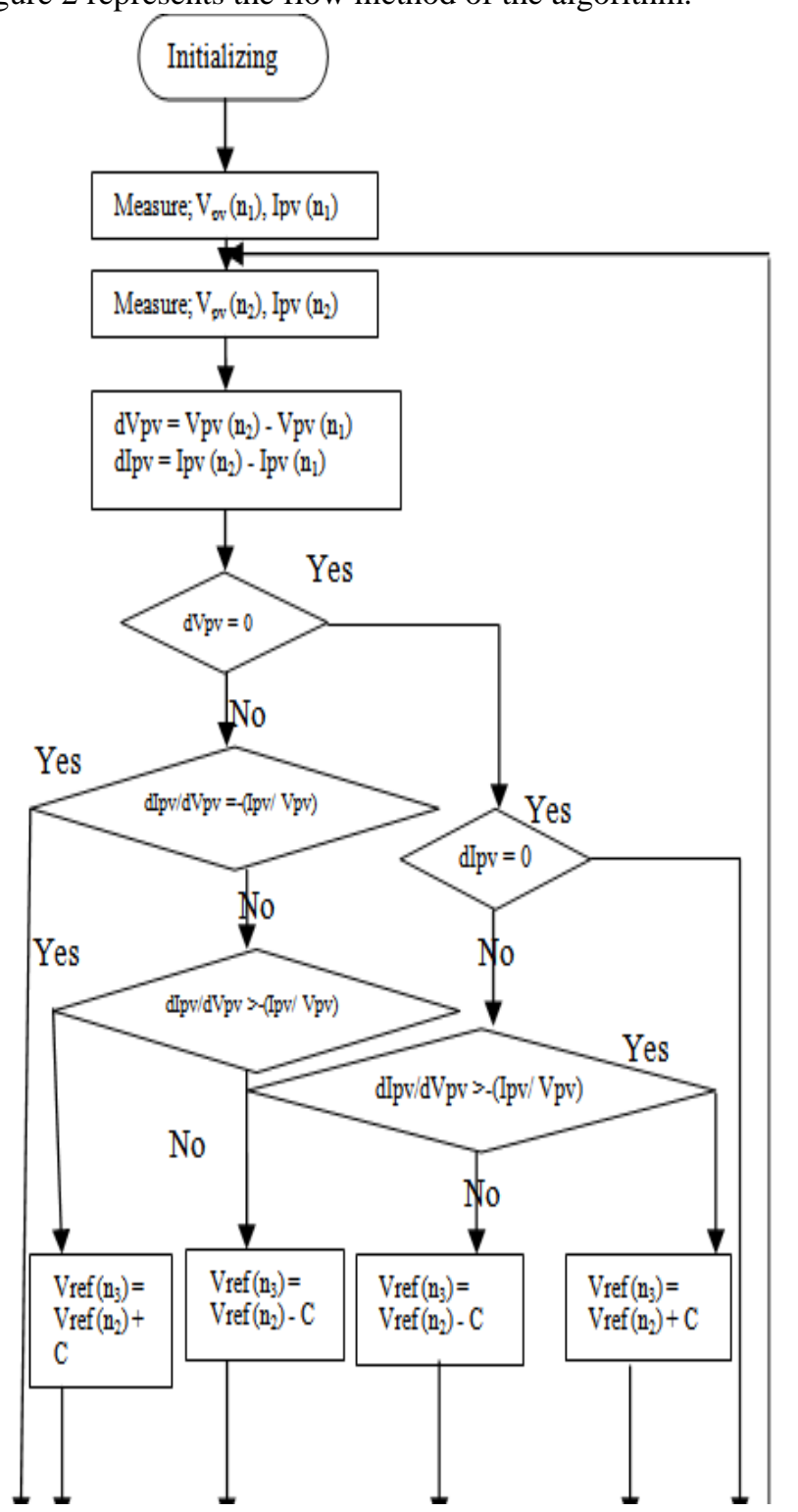

Figure 2 Flow diagram of the algorithm used in MPPT control strategy

The algorithm uses 2 equations (1) \& (2) are:

$$
\begin{aligned}
& \mathrm{dP} / \mathrm{dV}=\mathrm{dVI} / \mathrm{dV}=\mathrm{I}+\mathrm{VdI} / \mathrm{dV}=0 \\
& -(\mathrm{I} / \mathrm{V})=\mathrm{dI} / \mathrm{dV}
\end{aligned}
$$

In equation 2 left side negative sign represents the reverse of the instantaneous conductance i.e. $\mathrm{G}=\mathrm{I} / \mathrm{V}$, however the other side of in equation 2 signifies the rate of increase or incremental conductance. By the observation it can be identified if the PV operates near to its maximum power point or away from it and the conditions for this are given in equations (3), (4) \& (5).

$$
\begin{aligned}
& \mathrm{dP} / \mathrm{dV}>0 \text { for } \mathrm{V}<\mathrm{V}_{\mathrm{mp}} \\
& \mathrm{dP} / \mathrm{dV}=0 \text { for } \mathrm{V}=\mathrm{V}_{\mathrm{mp}} \\
& \mathrm{dP} / \mathrm{dV}<0 \text { for } \mathrm{V}>\mathrm{V}_{\mathrm{mp}}
\end{aligned}
$$

Under the changing ambient conditions the algorithm provides a good yield method as a benefit for the system. By the algorithm chattering is also decreases around the MPP. A complex control circuit requirement is a disadvantage of the algorithm as it form it costly. Though there are various methods to overcome the disadvantage which has been used in the project to reduce the cost.

\section{SIMULATION AND RESULT}

A software 'MATLAB' is used for the simulation and developing a relative model. The coding of present algorithm i.e. Incremental Conductance MPPT algorithm is done by the use of software. The Figure 3 illustrates a modelled representation of algorithm.

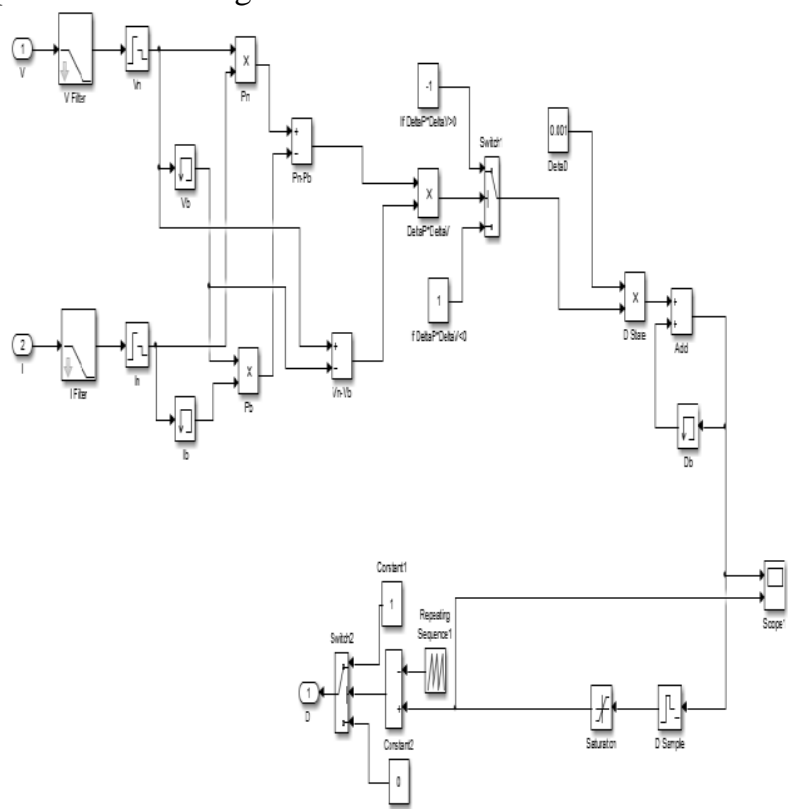

Figure 3modelled representation of algorithm

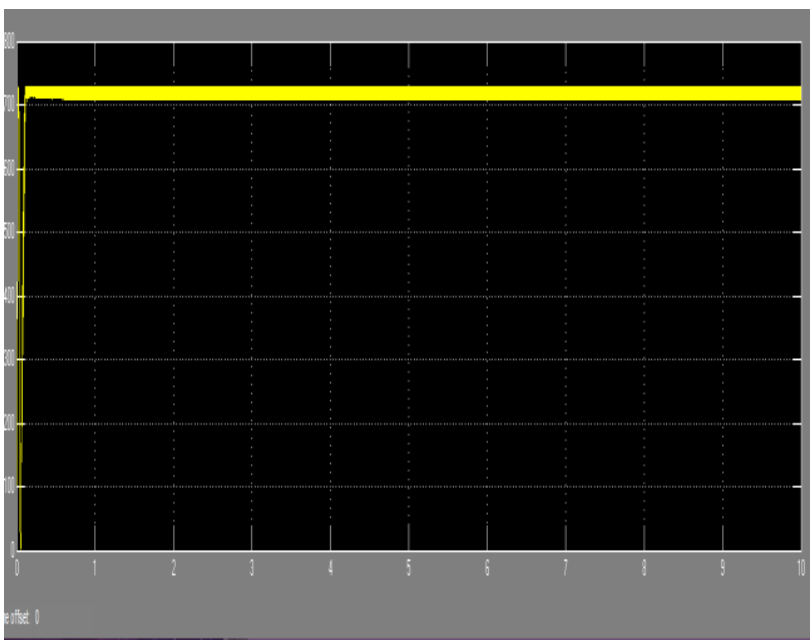

Fig. 4: PV output with MPPT

Published By:

Blue Eyes Intelligence Engineering

\& Sciences Publication 


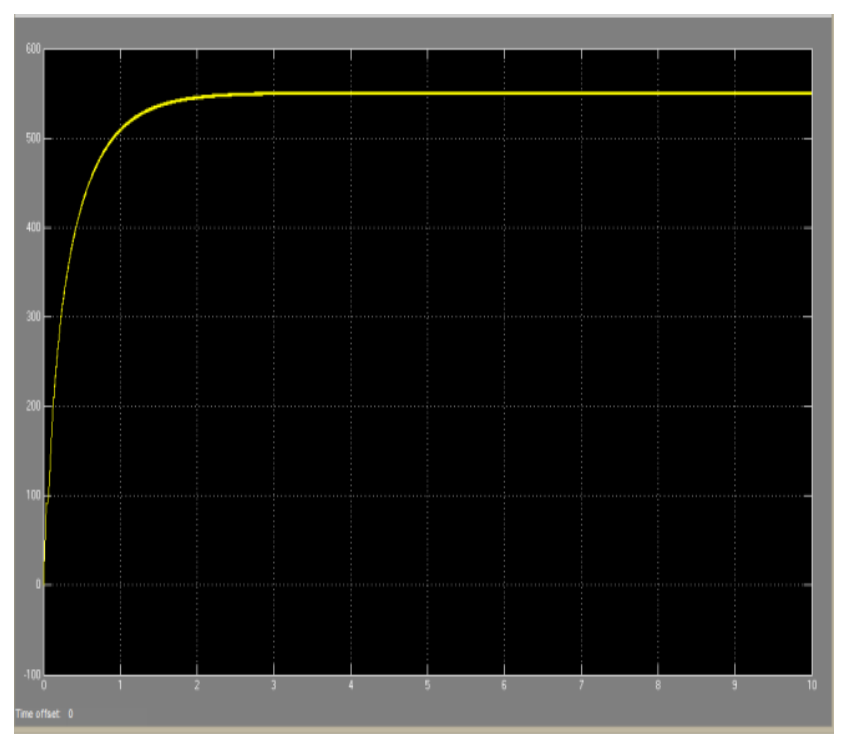

Fig. 5: PV system output without MPPT output

\section{ENTIRE SYSTEM SIMULATION\& RESULTS}

The simulation model involves a converter, PV module, and a MPP tracker that work on incremental conductance algorithm and the resistive type of load.

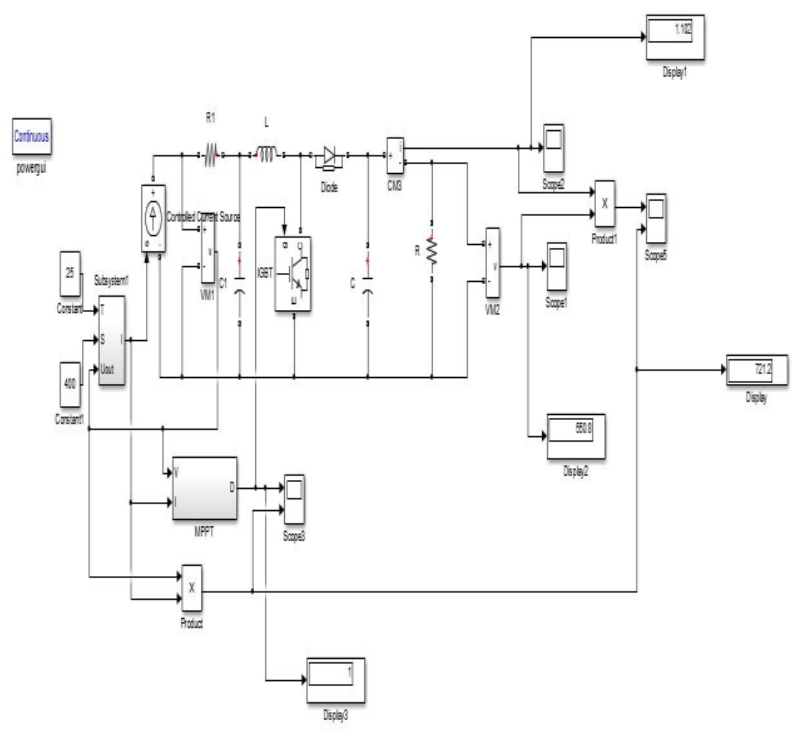

Fig. 6: Complete system simulink model

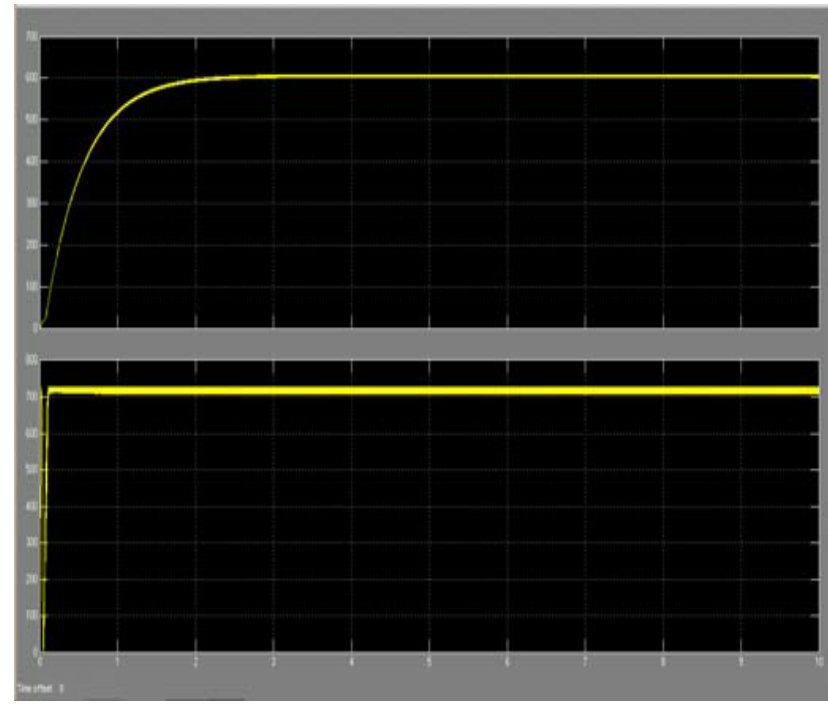

Fig. 7: Complete system output

\section{CONCLUSION}

The project work has been implemented on efficiency improvement of solar photovoltaic power system effectively, a PV model has been implemented using a MATLAB software and by doing simulation of the model. To track the maximum point of power an incremental conductance method is coded and simulated using the software. By observing the different results coming by the simulation it is concluded that the system is capable of extracting the maximum power by tracking maximum power point.

\section{REFERENCES}

1. V. Sumathi, R. Jayapragash, A. Bakshi, and P. Kumar Akella, "Solar tracking methods to maximize PV system output - A review of the methods adopted in recent decade," Renewable and Sustainable Energy Reviews. 2017.

2. R. Ramakumar and J. E. Bigger, "Photovoltaic Systems," Proc. IEEE, 1993.

3. H. Lund, "Renewable energy strategies for sustainable development," Energy, 2007.

4. U. Aswathanarayana, "Solar energy," in Green Energy: Technology, Economics and Policy, 2010.

5. D. P. Hohm and M. E. Ropp, "Comparative study of maximum power point tracking algorithms using an experimental, programmable, maximum power point tracking test bed," in Conference Record of the IEEE Photovoltaic Specialists Conference, 2000.

6. M. A. Eltawil and Z. Zhao, "MPPT techniques for photovoltaic applications," Renewable and Sustainable Energy Reviews. 2013.

7. A. Reza Reisi, M. Hassan Moradi, and S. Jamasb, "Classification and comparison of maximum power point tracking techniques for photovoltaic system: A review," Renewable and Sustainable Energy Reviews. 2013.

8. J. P. Ram, N. Rajasekar, and M. Miyatake, "Design and overview of maximum power point tracking techniques in wind and solar photovoltaic systems: A review," Renewable and Sustainable Energy Reviews. 2017. 